\title{
O lugar ocupado pela assistência fisioterapêutica: representações sociais de trabalhadores com DORT
}

\author{
The place occupied by physical therapy: \\ social representation of workers with WMSDS
}

\author{
Vanusa Caiafa Caetano ${ }^{[a]}$, Danielle Teles da Cruz $^{[b]}$, Girlene Alves da Silva ${ }^{[c]}$, \\ Isabel Cristina Gonçalves Leite ${ }^{[\mathrm{d}]}$
}

[a] Doutora em Saúde pela Universidade Federal de Juiz de Fora (UFJF), professora adjunta da Faculdade de Fisioterapia da Universidade Federal de Juiz de Fora (UFJF), Juiz de Fora, MG - Brasil, e-mail: vcaiafa@gmail.com

[b] Mestre em Saúde Coletiva, professora assistente da Faculdade de Medicina da Universidade Federal de Juiz de Fora (UFJF), Câmpus Avançado de Governador Valadares, Governador Valadares, MG - Brasil, e-mail: danielle.teles@ufjf.edu.br

[c] Doutora em Enfermagem pela Universidade de São Paulo (USP), professora adjunta da Faculdade de Enfermagem da Universidade Federal de Juiz de Fora (UFJF), Juiz de Fora, MG - Brasil, e-mail: girleneas@terra.com.br

[d] Doutora em Saúde Pública pela Escola Nacional de Saúde Pública, professora adjunta da Faculdade de Medicina da Universidade Federal de Juiz de Fora (UFJF), Juiz de Fora, MG - Brasil, e-mail: isabel.leite@ufjf.edu.br

\section{Resumo}

Introdução: Os distúrbios osteomusculares relacionados ao trabalho (DORT) articulam-se diretamente à realização de atividades ocupacionais e às condições de trabalho. Objetivo: 0 artigo origina-se de uma pesquisa qualitativa que analisou as representações sociais da assistência fisioterapêutica entre trabalhadores portadores de Distúrbios Osteomusculares Relacionados ao Trabalho (DORT), frequentadores do Centro de Referência em Saúde do Trabalhador (CEREST), pelo Departamento de Saúde do Trabalhador (DSAT), Juiz de Fora (MG). Materiais e métodos: 0 recurso de apreensão das informações foi a entrevista semiestruturada, realizada com 12 trabalhadoras com idades entre 29 e 55 anos. Resultados: As informações submetidas à análise temática apontaram que a assistência fisioterapêutica recebida repercute em períodos longos de tratamento e na insatisfação dos resultados, por meio de uma prática curativista, segmentada e pouco resolutiva, na qual prevalece a utilização de equipamentos em detrimento das manobras corporais e holísticas. Conclusão: Diante dos relatos, verificamos a necessidade de uma atenção 
humanizada, integral e equânime com responsabilização e vínculo, além da valorização dos trabalhadores e usuários, promovendo melhor qualidade de vida. É imprescindível a realização de novos estudos que possibilitem melhor compreensão e aprofundamento teórico e prático da relação entre a atuação do fisioterapeuta e as representações sociais envolvidas.

Palavras-chave: Fisioterapia. DORT. Representação social. Saúde do trabalhador.

\section{Abstract}

Introduction: The work-related musculoskeletal disorders (WMSDS) are articulated directly to occupational activities and working conditions. Objective: The article developed from a qualitative study that analyzed the social representation of physical therapy among workers with Work-Related Musculoskeletal Disorders (WMSDS), users of the Reference Center for Occupational Health (CEREST - Centro de Referência em Saúde do Trabalhador), through the Department of Occupational Health (DSAT - Departamento de Saúde do Trabalhador), Juiz de Fora (MG). Materials and methods: The resource of capturing the information was the semi-structured interview, conducted with 12 workers aged between 29 and 55 years old. Results: The information submitted to thematic analysis indicate that physical therapy received echoes over long periods of treatment, and dissatisfaction of the results, through a curative practice, targeted and little resolving, in which prevails the use of equipment at the expense of bodily and holistic maneuvers. Conclusion: Whereupon the report, we found the need for humanized care, whole and equal with accountability and commitment, in addition to the appreciation of workers and users, promoting better quality of life. It is essential carrying out further studies to enable a better understanding as well as theoretical and practical deepening of the relation between the role of the physiotherapist and the social representation involved.

Keywords: Physical therapy. WMSDS. Social representation. Occupational health.

\section{Introdução}

A saúde do trabalhador encontra-se diretamente relacionada a fatores econômicos, sociais, tecnológicos e organizacionais engrenados ao perfil de produção e consumo, além dos fatores de risco de natureza física, química, biológica, mecânica e ergonômica presentes nos processos laborais produtivos. Os distúrbios osteomusculares relacionados ao trabalho (DORT) articulam-se diretamente à realização de atividades ocupacionais e às condições de trabalho (1).

Os trabalhadores com DORT deparam-se com várias dificuldades diariamente, como: dor; limitações físicas; desrespeito e desconfiança por parte dos empregadores; humilhação e menosprezo observados na relação com médicos peritos do Instituto Nacional do Seguro Social (INSS); incompreensão da família; perda da capacidade laboral, dentre outras situações, de acordo com os apontamentos de Borsoi, Santos e Acário (2).

Os DORT são considerados uma epidemia mundial, de tratamento clínico e fisioterapêutico com difícil resolução, em virtude de sua gênese patológica multifatorial (3). Ikari et al. (4) referenciam que há poucos estudos sobre prevenção e intervenções na área da fisioterapia, havendo evidências de melhora dos sintomas na maioria dos estudos; porém, não há homogeneidade quanto aos tipos de intervenção. Assim sendo, os trabalhadores ficam a mercê de um diagnóstico incerto e de exaustivos tratamentos ineficazes.

Como consequência, esses indivíduos tornam-se incapacitados para a atividade laboral, repercutindo em estados e sentimentos de tristeza, angústia, depressão e impotência diante desse problema e da impossibilidade de ascensão social (4).

Os trabalhadores portadores de DORT, afastados pelo INSS, oneram com diagnósticos e tratamentos que não consideram a questão primordial dos diferentes aspectos da saúde desses trabalhadores adoecidos. Consequentemente, sobrecarregam as instituições previdenciárias com aposentadorias e indenizações, gerando grande impacto social e financeiro (5).

0 conceito de representação social emerge como importante ferramenta nesse campo, uma vez que possibilita a integração de aspectos implícitos e 
explícitos do comportamento dos indivíduos, resultantes da interação social, o que nos leva à compreensão da realidade e dos fenômenos humanos a partir de uma perspectiva coletiva, sem perder o olhar da individualidade $(6,7)$.

Lançar mão da teoria da representação social para a compreensão do universo que abarca a saúde do trabalhador e as representações dos trabalhadores com DORT acerca da assistência fisioterapêutica configura-se como elo entre as interfaces do processo saúde-adoecimento e os serviços de saúde destinados a essa parcela da população.

Tendo em vista o exposto, acreditamos que o estudo das representações sociais da assistência fisioterapêutica fornece-nos um campo fértil para a aquisição de conhecimento, interpretação e reflexão de diferentes olhares, valores, interesses, posições e práticas que circulam entre os trabalhadores portadores desse agravo.

Nesse contexto, esta pesquisa teve como objetivo analisar as representações sociais da assistência fisioterapêutica entre os trabalhadores portadores de DORT na cidade de Juiz de Fora (MG) e macrorregião.

\section{Materiais e métodos}

0 presente estudo foi desenvolvido numa abordagem qualitativa, utilizando-se como referencial teórico a teoria das representações sociais (8), que busca conhecer e trabalhar aspectos particulares do universo dos significados, valores e atitudes, que compreendem o espaço das relações e fenômenos desses trabalhadores (9).

Realizamos a coleta de dados por meio de entrevista semiestruturada, que combinou a condução da abordagem à liberdade do trabalhador entrevistado em expor seus pensamentos, garantindo a espontaneidade das falas. Novas perguntas puderam ser incorporadas quando havia a necessidade de aprofundar determinado assunto ou de reajustar uma linha de pensamento. Cada entrevista foi realizada de forma individual com o trabalhador participante, e registradas por um microgravador.

A pesquisa foi realizada com trabalhadores afastados, usuários do Sistema Único de Saúde (SUS), inseridos no Programa de Reabilitação Física do Centro de Referência em Saúde do Trabalhador (CEREST), pelo Departamento de Saúde do Trabalhador (DSAT), Prefeitura Municipal de Juiz de Fora, Secretaria de
Saúde do município de Juiz de Fora (MG). Para serem inseridos nesse programa, os trabalhadores devem ter uma renda mensal de até três salários mínimos, não havendo a obrigatoriedade de vínculo empregatício. Uma vez inseridos, esses indivíduos recebem mensalmente auxílio para transporte, dentro de uma trajetória de intervenções feita pelo DSAT.

Os entrevistados foram escolhidos a partir de um estudo quantitativo previamente realizado entre os trabalhadores inseridos no Programa de Reabilitação Física do CEREST. Foram selecionados para o estudo trabalhadores com nexo ocupacional de DORT, cadastrados e frequentes no referido programa desde o ano de 2006, que estavam em tratamento fisioterapêutico.

Segundo Turato (10), o número de participantes deve buscar, propositalmente, indivíduos que vivenciam o problema em foco e/ou têm conhecimento sobre ele. Foram entrevistadas 12 trabalhadoras, cuja idade variou entre 29 e 55 anos; caracterizadas de maneira que o anonimato permanecesse preservado, identificadas por suas iniciais. Desempenhavam diversas categorias profissionais, com renda mensal em torno de um salário mínimo: costureiras (três), domésticas (duas), serviços gerais (duas), auxiliar de fisioterapia, faxineira, operadora de caixa, secretária de digitação e enroladeira de papel higiênico. Verificamos que as trabalhadoras iniciaram suas vidas profissionais precocemente - a idade mínima descrita foi de 6 anos, e a máxima, 14 anos de idade, ambas consideradas como trabalho infantil.

0 número de entrevistas encerrou quando as informações alcançadas foram consideradas suficientes e atingiram a chamada saturação, exaustão ou ponto de redundância (11), isto é, quando os temas e/ou argumentos começaram a se repetir, lembrando, conforme Minayo (9), que grandes números só seriam necessários para controle estatístico das variáveis.

Os participantes receberam informações sobre a pesquisa e, após concordarem em participar, assinaram o termo de consentimento livre e esclarecido, aprovado pelo Comitê de Ética e Pesquisa (CEP) da Universidade Federal de Juiz de Fora (UFJF), sob o parecer n. 326/2007.

Seguimos como referência as três etapas cronológicas sugeridas por Bardin (12), para a organização da análise dos discursos: pré-análise, descrição analítica e interpretação inferencial. Após sua realização, as entrevistas foram transcritas em sua íntegra, analisadas em profundidade, com a definição de blocos temáticos. Inicialmente, os aspectos abordados pelos 
trabalhadores foram analisados, buscando as reincidências das informações e os temas nomeados.

Uma vez categorizadas as falas dos trabalhadores entrevistados, mediante os objetivos propostos, foram feitas as inferências necessárias com base na literatura científica, visando alcançar o objetivo deste estudo.

Os resultados da análise das representações sociais da Fisioterapia entre trabalhadores com DORT serão apresentados com os depoimentos apresentados em blocos temáticos.

\section{Resultados e discussão}

Seguindo as proposições para análise e interpretação dos dados, foram construídos e nomeados os blocos temáticos abaixo descritos de forma a expressar o conteúdo presente nas representações sociais das trabalhadoras envolvidas. No primeiro, abordamos a assistência fisioterapêutica representada pelas entrevistadas, destacando a satisfação e a insatisfação das trabalhadoras perante a assistência recebida; e no segundo, apresentamos o atendimento e o acesso aos serviços de atenção à saúde do trabalhador.

Bloco temático 1 - A representação da assistência fisioterapêutica

A literatura tem incluído a análise da satisfação dos usuários do SUS como um potencial indicador da qualidade da atenção à saúde. Entretanto, os aspectos de satisfação do paciente e sua opinião ainda encontram espaço a ser investigado no meio científico, contemplando mais a qualidade técnica das especialidades clínicas (13).

A assistência fisioterapêutica representada nas falas demonstra características que podem influenciar a satisfação recebida pelas usuárias. Nos discursos, algumas participantes referem melhora com a assistência fisioterapêutica recebida, outras referem benefício passageiro, relatando dependência do tratamento e uma critica o pouco tempo de aplicação dos recursos, admitindo-os insuficientes para o benefício duradouro, como retratam os recortes das entrevistas:

[...] Quando eu faço fisioterapia melhora bem a dor, eu estou fazendo a fisioterapia [...] passei dois meses sem fazer, foi quando a dor voltou, tinha melhorado bem. [...] Aí não posso ficar sem fazer [...] (DRL);
[...] Assim... eu sinto uma melhora. Ah! Eu me sinto bem, ela passa o ultrassom, aí eu me sinto bem. Ainda falei com ela que quando eu saio, chega lá fora, volta a doer, mas não é assim... é que eu me sinto dependente. Na verdade, eu me sinto dependente da fisioterapia [...] (JSA).

[...] Quando estou fazendo, eu sinto uma melhora, mas parou de fazer, começa a doer tudo de novo. Lá onde que eu faço, eles colocam muito pouco tempo. Eles falam que colocam dez minutos, mas não são dez minutos: são cinco minutos de ondas curtas, cinco minutos de choquinho, ultrassom não é nem dois minutos. Passa o gel, passa o ultrassom, acabou... Umas três rodadas, e acabou. A sessão mesmo não dura nem 15 minutos... é muito rápido, é muito rápido, estou sendo sincera (ARR).

A satisfação dos usuários com os serviços de fisioterapia pode ser considerada, já que essa especialidade reabilita as alterações ocasionadas pelos distúrbios cinético-funcionais, levando a sintomas traumato-ortopédicos, comumente encontrados em trabalhadores comprometidos com DORT (13).

Ikari (4) et al. apontaram grande variedade de intervenções fisioterapêuticas, dentre as quais se destacaram: fisioterapia convencional; treinamento de força, resistência e coordenação; programa individual de treinamento físico; alinhamento postural; diminuição da tensão neural; fortalecimento e alongamento; readequação ergonômica do ambiente de trabalho; grupos terapêuticos; orientações para exercícios; informações sobre DORT. Verificaram evidências de melhora dos sintomas, não havendo, no entanto, uma homogeneidade nos tipos de intervenção, levando-os a ressaltar a prevenção como a melhor opção para esses trabalhadores.

No que diz respeito ao tratamento do paciente portador de DORT, são evidentes os obstáculos encontrados pelos fisioterapeutas para executar essas atividades. A invisibilidade dos distúrbios, a evolução clínica imprevisível e a subjetividade da dor interferem drasticamente na definição de um plano de tratamento adequado (14).

As dificuldades advindas da assistência fisioterapêutica repercutem em períodos longos de tratamentos e na insatisfação dos resultados por parte das trabalhadoras com DORT, apesar de, ambiguamente, admitirem alívio dos sintomas, segundo depoimentos a seguir: 
[...] Gostar, gostar, eu não gosto não... (risos) porque já estive até irritada, porque todo dia ter que sair de casa e fazer aquilo, durante uns 15 dias. Aquelas coisas que a gente faz lá, a gente faz até em casa. Botar a mão na água, fazer exercício [...]. O calor do abajur (risos) também... (LMBM).

[...] Você tem que fazer umas trinta sessões, até mais para você ter um resultado, um pouco de alívio da dor... um pouco de alívio. Até alivia aquele tempo ali, mas se vocêfica dois, três meses sem fazer, volta novamente. Eu vejo assim, eu tenho que viver para o resto da vida com a fisioterapia, entendeu? (EANL).

[...] Ah! eu já estou ficando cansada. Sinceramente, o tratamento em si é chato, of fato de você ter que se deslocar pra ir. Alivia um pouco... (MFE).

Encontramos, de modo quase equivalente, a menção da insatisfação quanto aos períodos longos de tratamento, evidenciando um problema advindo das características da doença, em função das limitações físicas, que afetam diretamente a qualidade de vida das trabalhadoras dentro de um contexto social.

Esse sentimento pode ser explicado pela visão reducionista do modelo biomédico adotado, por não considerar as dimensões sociais, psicológicas e comportamentais capazes de influenciar a doença (14).

As possibilidades de atuação do fisioterapeuta têm caminhado para maior adequação à política pública de saúde preconizada pelo SUS, na qual a valorização de prevenção e promoção da saúde e maior resolutividade dos atendimentos prestados representam um dos elementos norteadores das ações propostas (15).

Nas representações das participantes, percebemos certa reprodução da prática curativista, segmentada e pouco resolutiva, em que prevalece a utilização de equipamentos em detrimento das manobras corporais e holísticas:

[...] Acho que eles deveriam fazer exercício para poder esticar, entendeu? Porque eu sinto muita dor nas costas (ARL).

[...] Elas não dão atenção pra gente... elas ficam andando, você tem que ficar batendo na parede pra chamar alguém. Elas não ficam lá perto da gente. Exercício, eu não faço, tem que fazer sozinha, elas não ficam perto, aí dói para rodar a roldana. Eu não aguento, porque aí dói, entendeu? Tinha que ter uma pessoa para te orientar lá, né? Ajudar a rodar aquele "trem" lá... (AMS).

[...] É assim... nunca fiz massagem não, só os aparelhos que eu uso lá... ninguém nunca me pôs a mão. Era bom se tivesse uma pessoa que... fizesse massagem, alguma coisa assim, alguma coisa que... sei lá... Por exemplo, o braço, às vezes, quando está dormente, eu passo a mão e dá um alívio, passo a mão devagarzinho no ombro, aí eu me sinto bem... (EANL).

Para muitos usuários do serviço público, a qualidade no atendimento não está centrada em técnicas ou recursos físicos de alta tecnologia, mas na atenção desprendida ao ser humano (13).

As representações elaboradas pelos usuários mostram que a maneira como a assistência fisioterapêutica é operada ainda centra-se na resolução do problema de uma parte específica do corpo, e não numa valorização do sujeito integralmente.

0 trabalhador portador de DORT deve ser visto de forma ampla, e não fragmentado em sintomas que reproduzem um modelo clínico reducionista, voltado somente para uma pequena parte do objeto: a doença e suas sequelas. Essa visão fragmentada reflete-se no perfil acadêmico do fisioterapeuta: muitos se voltam apenas para o processo de cura e reabilitação, com ênfase no modelo biomédico e individualista (16).

Augusto (14) et al. verificaram que a visão dos fisioterapeutas quanto à etiologia dos DORT encontra-se restrita, uma vez que desconsideram as atividades laborais como elemento importante dentro da multicausalidade do processo de adoecimento. Nessa perspectiva, é imprescindível considerar o indivíduo como um ser provido de aspirações, anseios e necessidades, inserido em um contexto social, ambiental, cultural e político. Assim, seguramente os resultados da assistência serão satisfatórios.

Alguns achados na literatura ressaltam a importância da reeducação postural e do reconhecimento dos próprios limites físicos, destacando a importância de uma rotina diária de exercícios físicos, que visa aumentar a flexibilidade, resistência e, consequentemente, melhora da capacidade funcional e residual do quadro álgico (17).

Percebemos, nos trechos a seguir, a ausência de tais atividades na assistência fisioterapêutica recebida pelas trabalhadoras e, até mesmo, um desconhecimento delas: 
[...] Ah! um tipo de exercício! Um alongamento, outro para ver se mexe mais assim, para ver o que eu vou sentir... Um exercício mais confortável (MFE).

Olha... Uma coisa que eu gostaria muito de fazer (mas se fosse para fazer lá, eu não faria) é a hidroginástica. Porque o Sistema Único de Saúde, infelizmente, a gente vê que questão de higiene é zero (SMSR).

[...] Eu não sei se tem que fazer mais exercício. Eu faço lá o que elas passam, mas a gente fica sem orientação, né? Eu faço sozinha. Em casa, ponho só gelo (LAS).

Questões como o processo de educação em saúde, orientações domiciliares e incentivos da autonomia, como estratégias importantes para a promoção da saúde, não foram contempladas na prática desses profissionais. No estudo de Augusto (14) et al., foi verificada a relevância de fatores fundamentais para melhor qualidade de tratamento e prevenção dos DORT, segundo a percepção dos fisioterapeutas, destacando postura e posicionamento adequados no trabalho, bem como a prática de exercícios e alongamentos.

Intervenções fisioterapêuticas adequadas frequentemente demandam maior tempo de atendimento, envolvendo o contato físico com participação interativa entre paciente e terapeuta. Tais dimensões estão correlacionadas com a satisfação do paciente, e a comunicação configura-se como o principal elo que permeia os diversos aspectos do processo de assistência profissional (13).

Verificamos que a percepção da qualidade da assistência na reabilitação também é influenciada pelas manifestações de preocupação e atenção, por aspectos da relação interpessoal os quais ocorrem durante os atendimentos de fisioterapia (13), representando a satisfação entre as entrevistadas a seguir:

[...] As meninas são... elas têm paciência, elas são muito boas, pelo menos comigo, eu nunca tive problema com nenhuma fisioterapeuta. Eu faço a fisioterapia e alivia (EIPM).

[...] Então... Isso ajuda bastante na psicologia, na cabeça da gente. Você encontra com amigo, conversa um pouquinho, lá na fisioterapia mesmo a gente conversa bastante. É bom... eu gosto de fazer, faço lanche na rua (risos). A fisioterapia é boa (AMS).
[...] Então... Está sendo muito bom também. Eles (fisioterapeutas) conversam muito com a gente, explicam como deve fazer [...]. Eu melhorei bem, eu sentia uma dor insuportável aqui assim (na face), repuxava e qualquer esforço que eu fazia eu sentia essa dor (DRL).

Diante do relato dessas trabalhadoras, é possível verificar a necessidade de uma atenção capaz de responder à sua demanda por saúde. Nesse sentido, estudos alegam que humanizar a atenção e a gestão em saúde no SUS é uma forma de qualificar as práticas de saúde, como o acesso com acolhimento, a atenção integral e equânime com responsabilização e vínculo, além da valorização dos trabalhadores e usuários (18).

Uma característica muito comum entre os portadores de DORT é a dor crônica, difusa, presente em diferentes partes do corpo. Esse quadro é reconhecido como wind up (ventania), no qual existe um espalhamento da dor, ou seja, ela é transferida do local acometido para local saudável por meio de movimentos antálgicos e adoção de determinadas posturas (19). Esse é um aspecto valorizado pelos profissionais, conforme revelado pelas trabalhadoras entrevistadas, de acordo com os depoimentos:

[...] Eu quando falo de fisioterapia, o que eu penso é tipo um apoio. Porque elas variam também. Elas te perguntam se continua doendo, aí elas mudam que é para ver se ajuda também (EIPM).

[...] Aí eles vão mudando à medida que eu falo: "oh! Isso aí não está resolvendo não, estou saindo do mesmo jeito, não senti alívio nenhum". Aí eles vão mudando, e atualmente é o choquinho e o infra (SMSR).

[...] É igual o choquinho, eu sinto dor aqui, aqui... Aí eu falo com ela: "põe aqui pra mim". Às vezes ela põe aqui onde eu não sinto dor, entendeu? Tem que ficar falando. Ah! Na hora que eu estou fazendo o aparelho, como te falei, eu sinto uma melhora, mas é muito rápida (ARR).

Essa é uma prática bastante comum nos atendimentos fisioterapêuticos, conforme observado por Augusto (14) et al., como se o recurso físico aplicado fosse "correr" atrás da dor, impedindo sua distribuição para outras regiões. Para Driver (20), a intervenção fisioterapêutica requer um profissional apto a identificar e tratar um trabalhador com DORT de maneira holística, com conhecimento das implicações 
tanto no âmbito das disfunções mecânicas quanto nas questões psicossociais, incluindo satisfação no trabalho e mudanças do corpo em função da idade.

Nos relatos a seguir, podemos observar essas ponderações elencadas por Augusto (14) et al. e Driver (20):

[...] Isso já deve ter uns dois ou três anos. Ela me colocava na esteira, que ela falou que eu tava gorda, cheinha demais. Me colocava na bicicleta para não me dar dor no joelho. Quer dizer, o médico não pedia isso, mas ela falava: "vamos fazer isso para te ajudar... e te ajudar no seu tratamento. Porque quanto mais peso você tiver, mais vai forçar sua coluna". Aí, quer dizer, para mim aquele tempo era bom, só que depois trocou a fisioterapeuta aí... não voltou... (EIPM).

[...] Eu acho assim... Depois que eu fiz 40, a idade está aumentando e a dor está sendo pior (EANL).

É imprescindível pensarmos no desenvolvimento de recursos adaptativos para o resgate da autonomia dos trabalhadores portadores de DORT, por meio da atenção integral, que ultrapasse o modelo clínico individual, reconhecendo as limitações em outras dimensões, como a social e a emocional.

0 resgate da autonomia desses profissionais é elemento essencial para as práticas de promoção da saúde e para edificação e construção do SUS (21).

A falta de contratações por meio de concursos públicos na esfera municipal pública altera a composição das equipes que poderiam responder às necessidades de uma demanda crescente de adoecidos no SUS. 0 número de fisioterapeutas para atuar em serviços próprios é insuficiente, implicando em demora nos atendimentos, além dos problemas de infraestrutura e tempo de espera, o que corrobora com o estudo de Machado e Nogueira (22), conforme recorte abaixo:

[...] Eu acho que lá deveria ter mais aparelhos, porque a gente espera muito tempo. E o que desanima é o tempo que você fica parado lá, entendeu? Cada dia que eu vou lá, só lá dentro, eu devo ficar umas duas horas por aí.. Esperando, esperando e fazendo. E ainda tem o ônibus que demora demais. Para ir e voltar, eu gasto umas quatro horas (EIPM).

É preciso também considerar que o efeito insuficiente da assistência fisioterapêutica recebida entre as trabalhadoras entrevistadas, pode associar-se ao grau de limitação proporcionado pela gravidade do próprio adoecimento, somado à falta de continuidade da assistência recebida.

[...] A fisioterapia, na verdade, para mim é tudo. Eu gostaria de fazer mais vezes. Porque eu tenho certeza que se eu fizesse o tratamento adequado, ali, todo mês direitinho, talvez eu já pudesse estar na minha vida normal há mais tempo e não estar assim desse jeito até hoje, né? Realmente cada pessoa tem um organismo... Então cada pessoa reage ao tratamento de uma forma. Eu saía de lá do mesmo jeito (SMSR).

[...] Alivia a dor um bocado, aí quando eu paro de fazer, tenho que ficar esperando, agendar o vale-transporte para poder pegar. Vamos supor assim... Se você marca a fisioterapia hoje, aí o vale sai só daqui um mês (MJBS).

É importante ressaltar que a atuação do fisioterapeuta pode ser desenvolvida nos diversos níveis de atenção à saúde, sobre os quais incorpora a abrangência da complexidade da atenção ao indivíduo e a importância dos diferentes conhecimentos no processo de reabilitação.

Diante da necessidade de atenção integral à saúde e de ampliação e qualificação das equipes multiprofissionais que atuam nos serviços públicos de saúde, o Ministério da Saúde, pela Portaria n. 145/GM, de 24 de janeiro de 2008, propõe a criação dos Núcleos de Apoio à Saúde da Família (NASF) para atuarem de forma integrada com toda a rede de serviços de saúde do sistema público, por meio de mecanismos de referência e contrarreferência. A criação do NASF prevê a participação do fisioterapeuta nessas equipes de saúde (23).

A experiência, o sentimento e a história de cada trabalhadora são fatores que devem ser reconhecidos no desenvolvimento das estratégias de intervenção terapêutica, conciliados com a expressão subjetiva do paciente (14). Emerge-se a necessidade de uma revisão e análise crítica e reflexiva sobre as práticas fisioterapêuticas empregadas atualmente, almejando uma assistência humanizada, integral e equânime em conformidade com os princípios e as diretrizes do SUS, bem como as políticas públicas de saúde vigentes.

Bloco temático 2 - O atendimento e o acesso aos serviços de atenção à saúde do trabalhador

Nesta categoria, procuramos analisar como as representações sobre o atendimento e o acesso se 
articula com a busca pelos serviços de atenção à saúde do trabalhador. As trabalhadoras apontam dificuldades de acesso aos serviços assistenciais do SUS, o que causa o agravamento da doença em função de um diagnóstico tardio e contratempos nos tratamentos, além da insatisfação com os atendimentos médicos.

[...] As consultas no SUS, hum..., assim, problemáticas demais, demora muito até você ter uma consulta. Quando eu fico dois meses sem fazer fisioterapia, aí volta, fico atacada de novo, as dores começam a voltar, aquela dor intensa, entendeu? Uma fisioterapia direta teria às vezes um resultado melhor... (EANL).

[...] Entrei com exame do braço em 2005... Só em 2008 saiu para eu fazer o exame. Demorou três anos, aí quando eu levei no médico, ele olhou e falou: "isso aqui não vale mais nada". Eu me senti humilhada. Ele falou: "seu exame aqui não tem valor nenhum". Então, aquilo para mim foi uma humilhação! (MJBS).

[...] Infelizmente, os médicos do SUS atendem muito mal, muito mal mesmo!. Você sai dali e já está assim... Quando está sentindo as coisas, já está por baixo, quando faz isso com a gente, a gente vai para o chão... A gente fica sem chão, completamente sem chão... E são vários (médicos) que fazem isso (DRL).

Diante do exposto, podemos perceber o alto grau de desarticulação das práticas e serviços de saúde, contrapondo ao princípio da integralidade proposto pela Reforma Sanitária e pelo advento do SUS.

O princípio da integralidade é desrespeitado não só pela falta de uma atenção á saúde integral e contínua, mas também pela presença de práticas fragmentadas e reducionistas, nas quais não é verificada a busca pela compreensão holística do indivíduo e há ainda a presença de um modelo biomédico e individualista $(24,25)$.

Já vimos anteriormente que a assistência fisioterapêutica tem sido prestada às vezes de forma "equivocada" e com baixa resolutividade, o que gera descrédito por parte dos médicos quanto a esse tipo de assistência:

[...] Aí ele (médico) falou assim comigo: "A fisioterapia não vai fazer efeito nunca, porque já não faz e você trabalhando é pior ainda..." (EIPM).

Dessa forma, entendendo a complexidade do processo de saúde-doença, devemos buscar o trabalho multidisciplinar, a autonomia de todos os profissionais de saúde e a troca constante de conhecimentos e saberes.

De acordo com dados da literatura científica, sabemos que existem inúmeros tratamentos fisioterapêuticos que permitem resultados positivos, como: redução do quadro álgico, melhora do estado geral e funções físicas, diminuição do absenteísmo, ganho de força muscular e resistência, melhora no controle motor, desempenho físico, diminuição do estresse ocupacional e aumento da produção. Cabe ressaltar, ainda, que a atuação de uma equipe multidisciplinar é essencial para a obtenção de resultados positivos (4).

Outro aspecto destacado pelas trabalhadoras foi em relação aos médicos peritos do INSS. A importância do reconhecimento da existência de doença e de sua repercussão foi descrito como fundamental numa boa relação profissional-paciente; a ausência desse aspecto é considerada por elas como um desrespeito:

[...] Eu não aguento fazer perícia, dá nervoso. Eu não sei, eu tenho medo toda vez que eu vou lá. Eu não gosto do perito. Eles puxam muito meu braço, apertam, puxam pra lá, puxam pra cá, mandam eu levantar meu braço. Eu não levanto o braço... Eu quase morro, incha tudo, isso nem cabe no meu braço (tipoia), incha tudo. $O$ perito tortura muito a gente, demais, falta só perguntar o que você come. Eu tenho pavor de fazer perícia! (AMS).

[...] Igual ao perito... Falou que sugeria me reabilitar. Eu respondi pra ele, eu fui sincera e falei: "Doutor! O senhor vai me reabilitar em quê? As mãos nada valem... a cabeça, pior ainda, que reabilitação que o senhor pensa em me dar?". Porque eu preciso das mãos e da cabeça também, para pensar. Eu falei com ele: "Está tudo ruim, está tudo ruim, você entendeu?" (EIPM).

As representações das trabalhadoras acerca dos atos periciais revelam a ausência de uma atitude investigativa sobre o processo saúde-doença no ambiente de trabalho. Mostra, ainda, o desrespeito às queixas das trabalhadoras, característica do modelo biomédico que valoriza e se detém meramente aos aspectos físicos do adoecimento.

O significado desse adoecimento e da incapacidade laboral destaca uma lacuna extremamente dolorosa para o indivíduo: a destruição de projetos de vida. Esse fato culmina na perda significativa da 
identidade pessoal e profissional, já que elas deixaram de ser respondidas pelo meio social em função das transformações impostas pela doença $(26,27)$.

Segundo Melo e Assunção (28), a decisão pericial diz respeito à existência ou não de doença, incapacitante ou não, tendo em vista exigências específicas da atividade profissional do segurado, podendo resultar, ou não, no deferimento do benefício por incapacidade pleiteado, em conformidade com a legislação vigente.

Takahashi e Iguri (29) consideram que as práticas atuais de reabilitação estão atreladas à regulação econômica do sistema pela contenção de despesas com benefícios e distanciadas da proteção social dos trabalhadores. Na realidade, os trabalhores encontram-se desassistidos de reabilitação profissional, o que corrobora para o aumento da sua desvantagem social por ocasião do retorno do trabalho (30).

\section{Considerações finais}

A visão estritamente fisiopatológica dos DORT, baseada no modelo biomédico, não apresenta resultados satisfatórios e eficazes da assistência fisioterapêutica conforme representado pelas trabalhadoras entrevistadas. Essa abordagem adotada acarreta na não resolução dos quadros álgicos, períodos extensos de tratamento fisioterapêutico, sobrecargas dos serviços públicos de saúde e repercussões no âmbito emocional e socioeconômico dessas trabalhadoras.

Em virtude do pensamento reducionista na assistência ao tratamento dos trabalhadores com DORT, emerge a necessidade de equipes interdisciplinares aptas e devidamente qualificadas para atender esses trabalhadores. Dentro dessa perspectiva, a contribuição do fisioterapeuta pode ser elemento importante para a consolidação de tal construto, desde que sua prática seja permeada pelos princípios da integralidade e da equidade.

No entanto, o que observamos é que a prática desse profissional encontra-se fragmentada e desarticulada com os princípios e as diretrizes que norteiam o SUS, contrapondo a políticas públicas de promoção da saúde e humanização, e violando o direto à saúde, garantido constitucionalmente.

Configurados como síndromes complexas, vistos de maneira fragmentada dentro de uma concepção mecanicista do organismo humano, e caracterizados por seus sintomas subjetivos e pela ausência de sinais clínicos objetivos, os DORT representam na íntegra, do ponto de vista da saúde pública, um grave problema que demanda atenção e medidas de caráter emergencial.

É fundamental a transformação das práticas hegemônicas, baseadas em modelo biomédico e curativista, para a implementação de práticas que priorizem a visão holística e integrada do trabalhador portador de DORT, objetivando, assim, a garantia do bem-estar e da qualidade de vida desses indivíduos.

\section{Referências}

1. Ragasson CAP. Qualidade no trabalho: estudo das condições de trabalho. Cascavel: Editora Coluna do Saber; 2004.

2. Borsoi ICF, Santos AOR, Acário SHA. Trabalhadores amedrontados, envergonhados e (in) válidos: violência e humilhação nas políticas de reabilitação por LER/DORT. RPP. 2006;16(12). [citado 22 maio 2009]. Disponível em: http://www.fafich.ufmg.br/rpp/seer/ ojs/viewissue.php?id=1/.

3. Araújo APS, Zampar R, Pinto SME. Auriculoterapia no tratamento de indivíduos acometidos por distúrbios osteomusculares relacionados ao trabalho (DORT) / lesões por esforços repetitivos (LER). Arq Ciênc Saúde Unipar. 2006;10(1):35-42.

4. Ikari TE, Mantelli M, Corrêa Filho HR, Monteiro MI. Tratamento de LER/DORT: intervenções fisioterápicas. Rev Cienc Med. 2007;16(4-6):233-43.

5. São Paulo. Poder legislativo. Debates - 13a Sessão Ordinária. Diário Oficial do Estado de São Paulo. 2006; 116(25):11-8. [citado 28 nov. 2012]. Disponível em: http://www.imprensaoficial.com.br/ PortalIO/DO/ BuscaD02001Documento_11_4.aspx? link=/2006/ legislativo/marco/18/pag_0011_4I1SOAU3APM1Fe CDVI26PA9SD8L.pdf\&pagina $=11 \&$ data $=18 / 03 / 200$ $6 \&$ caderno=Legislativo\&paginaordenacao $=10011$.

6. Silva FCM, Sampaio RF, Cabral LH, Augusto VG, Mancini MC. Representação social e reabilitação: considerações conceituais. Anais do X Congresso Brasileiro de Terapia Ocupacional. Contextos, territórios e diversidades, 2007, Goiânia.

7. Caetano VCC, Cruz DT, Leite ICG. Fisioterapia na saúde do trabalhador: um campo de análise da representação social. Cad Saúde Col. 2009;17(2):453-64. 
8. Jodelet D. As representações sociais: um domínio em expansão. In: Jodelet D, organizadora. As representações sociais. Rio de Janeiro: EDUERJ; 2001.

9. Minayo GC. O desafio do conhecimento: pesquisa qualitativa em saúde. 8. ed. São Paulo: Editora Hucitec; 2004.

10. Turato ER. Tratado da metodologia da pesquisa clínico-qualitativa: construção teórico-epistemiológica, discussão comparada e aplicação nas áreas da saúde e humanas. 2. ed. Petrópolis: Vozes; 2003.

11. Mazzoti AJ, Gewandsznajder F. O método nas ciências naturais e sociais: pesquisa quantitativa e qualitativa. 2. ed. São Paulo: Pioneira; 1998.

12. Bardin L. Análise de conteúdo. Lisboa: Edições 70; 1977.

13. Mendonça KMPP, Guerra RO. Desenvolvimento e validação de um instrumento de medida da satisfação do paciente com a fisioterapia. Rev Bras Fisioter. 2008;11(5):369-76.

14. Augusto VG, Sampaio RF, Tirado MGA, Mancini MC, ParreiraVF. Um olhar sobreas LER/DORT no contexto clínico do fisioterapeuta. Rev Bras Fisioter. 2008;12(1):4956. doi:10.1590/S1413-35552008000100010.

15. Rodrigues RM. A fisioterapia no contexto da política de saúde no Brasil: aproximações e desafios. Perspect Online. 2008;2(8):104-9.

16. Silva DJ, da Ros MA. Inserção de profissionais de fisioterapia na equipe de saúde da família e Sistema único de Saúde: desafios na formação. Rev Ci Saúde Col. 2007;12(6):1673-81.

17. Merlo ARC, Jacques MGC, Hoefel MGL. Trabalho de grupo com portadores de LER/DORT: um relato de experiência. Psicol Reflex Crit. 2001;14(1):253-8. doi:10.1590/S0102-79722001000100021

18. Benevides R, Passos E. A humanização como dimensão pública das políticas de saúde. Rev Ci Saúde Col. 2005;10(3):561-71.

19. Alencar JF, Coury HJCG, Oishi J. Aspectos relevantes no diagnóstico de DORT e fibromialgia. Rev Bras Fisioter. 2009;13(1):52-8. doi:10.1590/ S1413-35552009005000001.

20. Driver DF. Occupational and physical therapy for work-related upper extremity disorders: how we can influence outcomes [abstract]. Clin occup Envirom Med. 2006;5(2).
21. Teixeira PF, Vaz FAC, Campos FCC, Álvares J, Aguiar RAT, Oliveira VA. Autonomia como categoria central no conceito de promoção de saúde. Rev Ci Saúde Col. 2008;13 Supl.2:S2115-22.

22. Machado NP, Nogueira LT. Avaliação da satisfação dos usuários de serviços de fisioterapia. Rev Bras Fisioter. 2008;12(5):401-8.

23. Brasil. Ministério da Saúde. Portaria n. 154/GM, de 24 de janeiro de 2008. Cria os Núcleos de Apoio à Saúde da Família - NASF. Diário Oficial da União. Brasília. 2008;38-42.

24. Machado MFAS, Monteiro EMLM, Queiroz DT, Vieira NFC, Barroso MGT. Integralidade, formação de saúde, educação em saúde e as propostas do SUS - uma revisão conceitual. Rev Ci Saúde Col, 2007:12(2):335-42.

25. Mattos, RA. A integralidade na prática (ou sobre a prática da integralidade). Cad Saúde Pública. 2004; 20(5):1411-6.

26. Lima MEA, Araújo JNC, Lima FPA. LER-Dimensões ergonômicas e psicossociais. Belo Horizonte: Editora Health; 1996.

27. Merlo ARC, Jacques MGC, Hoefel MGL. Trabalho de grupo com portadores de LER/DORT: um relato de experiência. Psicol Reflex Crit. 2001;14(1):253-8. doi:10.1590/S0102-79722001000100021.

28. Melo MPP, Assunção AA. A decisão pericial no âmbito da Previdência Social. Physis: Rev Saúde Col. 2003; 13(2):105-27.

29. Takahashi MABC, Iguri AM. As mudanças nas práticas de reabilitação profissional da Previdência Social no Brasil: modernização ou enfraquecimento da proteção social? Cad. Saude Publica. 2008;24(11):2661-70. doi:10.1590/S0102-311X2008001100021.

30. Ghisleni AP, Merlo ARC. Trabalhador contemporâneo e patologias por hipersolicitação. Psicol Reflex Crit. 2005;18(2):171-6. doi:10.1590/S010279722005000200004 .

Recebido: 19/10/2011 Received: 10/19/2011

Aprovado: 16/01/2012 Approved: 01/16/2012 